\title{
A infervenção culfural do discurso cinematográfico: Os sentidos da ditadura militar no Brasil
}

\section{RESUMO}

Com a eclosão da ditadura militar em 1964, o silenciamento de vozes destoantes do poder firmou-se como regra. Diante da violência, grupos ligados à arte reagiram e tentaram, através do cinema, contar a história do país. A narrativa se construía a partir de roteiros reais: personagens eram tirados da vida para as telas. O drama foi perpetuado a partir de filmes produzidos durante e após o golpe. Após 40 anos, o cinema ainda revela significações da história que o discurso oficial se opunha, numa relação binária do bem contra o mal. Para compreensão desta construção discursiva, vamos analisar brevemente a produção do cinema relativa ao período.

\section{PALAVRAS-ChAVE}

Trauma cultural

Cinema

Ditadura

The cultural intervention of the cinematographic speech:

The meanings of military dictatorship in Brazil

\section{ABSTRACT}

After military Brazilian dictatorship in 1964, army force was the law and opposite discourse was silenced. However, in spite of such violent situation, artists reacted and tried, through the cinema, narrate the real Brazilian History. The narrative was constructed based on real stories: people were transposed from their real lives to movies. Drama was perpetuated through movies produced during and after military coup d'état. After 40 years, movies show meanings against the Brazilian official discourse and give to audience a binary association, as a fight between good and evil. Therefore, in order to understand this discussion in Brazilian films, we will make a brief analysis of the production in that period.

\section{KEY WORDS}

Cultural trauma

Cinema

Dictatorship

\author{
Patricia Bandeira de Melo \\ Pesquisadora da Fundacão Joaquim Nabuco - FUNDAJ/PE/BR \\ patricia.melo@fundaj.gov.br
}

O objetivo deste artigo é ilustrar o processo de intervenção cultural do discurso do cinema nacional acerca da ditadura militar no Brasil. A intenção é perceber que contratos de leitura são ofertados ao espectador pela produção cinematográfica sobre o golpe militar, a partir dos sentidos que são representados. Com a tomada do poder pelos militares, em 1964, a mídia - imprensa, televisão, rádio, cinema e literatura - passou por várias iniciativas de censura, que controlavam a produção artística, cultural e jornalística no Brasil.

Após mais de 40 anos, a mídia ainda explora a história do país, elaborando sentidos e construindo o drama social do período ditatorial. No cinema, a produção relativa à ditadura é expressiva após os anos 80 , mas até hoje ainda ocupa o imaginário dos cineastas, com obras recentes como os filmes Zuгu Angel e Cabra-cega, que serão observados neste trabalho.

Uma nova perspectiva teórica acerca do posicionamento da cultura na estrutura social permitiu uma ampliação do debate sobre a cultura. Embora muitas vezes dependa de fatores econômicos e políticos, a cultura pode ser vista como elemento detonador de mudanças sociais. A mídia - definida por Adorno (2002) como um sistema integrante da indústria cultural - é o espaço público contemporâneo, o palco de exposição das novas narrativas culturais. As sociedades pós-liberais liquidaram a essência de esfera pública definida por Habermas (1984) e a mídia vem substituindo o espaço.

Se, por um lado, o conceito de indústria cultural denota uma compreensão marxista de cultura, esboçando o determinismo da economia sobre a cultura, por outro, na perspectiva da sociologia cultural - explicada a seguir - a cultura aparece como variável determinante, capaz de influenciar a economia e a política. Esta perspectiva é inaugurada por autores como Alexander (2002a; 2002b), Sztompka (2000), Kane (1991; 2000) e outros que estão revigorando a ideia da cultura na estrutura social. 
Algumas considerações sobre cultura

A imporfância do cinema para a estrutura social é evidente, é grande seu potencial para gerar valores e discutir episódios históricos, construindo discursos sobre fatos sociais.

Foi assim com o cinema hollywoodiano e a construção narrativa de traumas culturais como o holocausto para os judeus, a escravidão para os negros africanos e as ditaduras na América Latina (Alexander, 2002c). O mesmo vem ocorrendo com o cinema brasileiro com relação ao golpe militar de 1964. Defendemos que a construção discursiva da ditadura feita pelo cinema vem estabelecendo o fato histórico como drama social nos últimos 40 anos e que pode evoluir para a produção do trauma cultural, como veremos adiante.

\section{A perspectiva que consideramos aqui é a de um cinema nacional que constrói um discurso de resistência contra a ditadura militar brasileira,}

elaborando uma narrativa acerca do episódio que é oferecida ao público como uma significação de conflito, terror, perseguição. Se concordarmos com a capacidade de subversão ou de adesão dos indivíduos, então, aceitamos que o cinema procura firmar um contrato de leitura1 com a audiência ao elaborar narrativas sobre o golpe militar, contrato que pode ou não ser aceito pelo público. Claro que não se sabe em que medida o indivíduo será autônomo para firmar esse contrato, sobre o qual irá influenciar a força tecnológica do meio e o seu poder simbólico.

Cada vez mais, os meios de comunicação ocupam o espaço de mediadores do conhecimento social circulante. Desde a concepção de esfera pública até a chegada da internet, observa-se o deslocamento do debate para a instância mediada (Habermas, 1984). É assim que o cinema vem elaborando sentidos acerca do período militar que serviram para mediar os fatos ocorridos nos 21 anos de ditadura. A audiência dos filmes, por sua vez, é formada muitas vezes por jovens que eram crianças ou que não haviam nascido à época.

Os veículos de mídia legitimam e produzem bens culturais resultantes de fragmentações dos significados dos quais se apropriam e colocam em circulação. A apreensão de sentidos pela audiência pode ser dominante (o modo hegemônico de perceber a informação), negociada (relacionando experiências vividas e o sentido hegemônico proposto) e opositiva (modo contrário ao proposto) (Barros Filho \& Martino, 2003). Logo, tudo o que é transmitido e posto em um quadro de significações não será recepcionado pelo público da forma como se espera. No caso do cinema sobre o golpe no Brasil, a narrativa que se sobressai aponta para o drama social dos que vivenciaram o golpe de modo que a audiência passe a compartilhar a mesma significação acerca do episódio.

Para os estudos culturais, a mídia é o lugar da produção da cultura, cultura já não mais entendida como pelos teóricos da Escola de Frankfurt, que a viam como um fenômeno do campo das ideias e reflexo das relações entre infraestrutura e superestrutura (Adorno, 2002). Os estudos culturais permanecem no determinismo econômico, mantendo a cultura como mercadoria na qual é retida a noção de ideologia como falsa consciência, como espaço para expressão das ideias dominantes de uma classe social. Para esta perspectiva teórica, a cultura não adquire o status merecido que somente vai ser concedido pela sociologia cultural, que a posiciona como elemento determinante na estrutura social.

A sociologia cultural

A sociologia cultural faz uma revisão da posição da cultura na estrutura social e oferece o conceito de trauma cultural para as ciências sociais. A nova ordem cultural na era da globalização produziu uma indústria cultural transnacional, colocando a cultura como propulsora da economia e da política. A perspectiva da Escola de Frankfurt - de visualizar a cultura como mercadoria - de fato se concretizou, mas agora numa perspectiva positiva: o aproveitamento da criatividade como forma de arregimentar riqueza ao mesmo tempo em que elabora narrativas críticas sobre os eventos históricos.

O cinema, o teatro, a literatura são áreas que ingressam no processo produtivo e são elementos da indústria cultural, seja como instrumento que gera 
capital, seja como instrumento de resistência. Alexander (2002a) funda, com a sociologia cultural, o conceito de cultura como uma variável reflexiva e diagnóstica de uma realidade. Para a sociologia cultural, a cultura é autônoma para moldar ações e instituições, constituída de rotina e criatividade que permitem a reprodução e a transformação da estrutura.

$\mathrm{Na}$ nova perspectiva, a realidade é um texto narrado pelos carrier groups, grupos condutores de discurso, que seriam, no caso deste artigo, os cineastas, os produtores e atores, os porta-vozes que assumem o papel de perpetuar a memória coletiva decorrente da ditadura militar, a partir de eventos considerados traumáticos para os indivíduos que vivenciaram o drama. Para Alexander (1993), a mídia é um recurso para investigação das representações coletivas em processos traumáticos de uma sociedade. Ele define trauma cultural:

Os traumas ocorrem quando indivíduos e grupos sentem que estão sujeitos a fatos horríveis que deixam marcas indeléveis sobre suas consciências, que marcarão suas memórias para sempre, e que vão mudar o futuro de modo fundamental e irrevogável (Alexander, 2002b, p. 01).

Numa perspectiva psicanalítica, um trauma pode deixar os indivíduos tão assustados que eles podem reprimir a experiência traumática por si mesmo. Mesmo experiências individuais traumáticas podem marcar gerações, se forem repassadas pelo grupo ao qual pertence o indivíduo. Alguns traumas podem emergir apenas após acompanhamento psicológico. Diferente do trauma individual, o trauma cultural ou coletivo é vivido por parte de um segmento social, mas ao ser publicizado e tratado pelos grupos condutores de discurso é que ganha status de drama social. Caso as significações sejam acatadas pela coletividade, o processo sai do nível de drama e ganha status de trauma cultural.

\section{A ditadura militar já é considerada um trauma culfural em países como Chile e Argentina. No Brasil, ainda há um processo em curso}

que tenta representar os episódios de violência e tortura como trauma cultural, processo narrativo que ajuda a legitimá-lo por meio da aclamação pública e da luta por reparação dos que foram torturados, mortos ou prejudicados. Os responsáveis por esta elaboração de sentido são os autores de um discurso que fundamenta os sentidos sobre o golpe militar como período de tortura, perseguição, morte, exceção, num processo simbólico complexo. Segundo Alexander (2002a), os carrier groups são lideranças que persuadem a audiência acerca de uma situação histórica a partir de recursos simbólicos disponíveis, como o cinema. Ele diz:

\begin{abstract}
Quando o processo de trauma ocupa espaço na mídia, torna-se sujeito não apenas da ética jornalística de concisão e neutralidade, mas também a competição por leitores que inspira a produção inexorável de notícias na circulação de jornais e revistas (Alexander, 2002a, p. 24).
\end{abstract}

O inovador no conceito de trauma cultural é a percepção da importância da cultura no processo. Numa sociedade, pode ser traumático uma revolução, um golpe de Estado, atos de terrorismo ou violência, limpeza étnica, assassinatos de líderes políticos ou a abertura de arquivos secretos. É este o momento histórico que o Brasil atravessa, a partir de 2010, com a criação da Comissão da Verdade pelo Governo Federal2, que tem o objetivo de apurar casos de violação de direitos humanos durante o regime militar, incluindo o levantamento de possíveis responsáveis. A polêmica sobre o estabelecimento ou não da comissão gerou inúmeros protestos, como o do advogado do Movimento dos Sem-Terra, Jacques Alfonsin:

É mais do que hora [...] de se defender essa Comissão da Verdade, para que as vergonhosas violações de direitos humanos, executadas por sucessivas ditaduras brasileiras, algumas registradas em publicações como "Brasil nunca mais" e "Batismo de sangue" (Frei Betto) [...] não sigam estimulando, escondidas em segredo oficial, a repetição de infidelidades históricas que o Estado brasileiro já praticou contra o seu povo (Alfonsin, Site www.cartamaior.com.br).

A autonomia da cultura 
A cultura, como rede de significação que guia a ação, torna-se capaz de interferir na vida social. Somente após a percepção desta autonomia em termos analíticos é que é possível descobrir em que caminhos a cultura intersecciona outras forças sociais, como o poder e a razão instrumental no mundo concreto. A cultura é um texto rico e complexo, com influência sobre a vida social. Os discursos operam de modos arbitrários para classificar o mundo e moldar a formação do conhecimento (Foucault, 1996). Na sociologia cultural, os sentidos são arbitrários, autônomos em relação à determinação social.

Há um processo de alteridade, no qual discursos e atores são tidos como detentores de autonomia na construção de identidades. Alexander sugere que o estruturalismo e a hermenêutica podem ser associados. O primeiro oferece as possibilidades de construção de uma teoria geral, predição e assertivas da autonomia da cultura. A segunda permite a análise para capturar a textura e o tempero da vida social. É a concepção da realidade como texto (a virada linguística) com a interpretação dos sentidos, no qual o ator social é o intermediário.

A cultura é um texto marcado por signos e símbolos em relação uns com os outros. O processo cultural é um ponto de intersecção entre estrutura e agência. Spillman e Jacobs (2005) destacam que a sociologia cultural não se limita a estudar sistemas de cultura especializados, como arte e mídia, possuindo potencial para análise de processos de produção de sentido de uma cultura total, com foco nas cognições, categorias e práticas, mais do que em valores e atitudes, uma ênfase sobre como os tipos de relações de poder (dominação e resistência) são mediados através do discurso.

Os sociólogos da sociologia cultural não ficam restritos aos sistemas culturais, mas colocam a cultura no centro de suas preocupações. As questões trazidas pela sociologia cultural são: a arte muda a sociedade? Em que circunstâncias isso acontece? Quando e como a cultura influencia a mudança social? Neste artigo, tendo o cinema nacional como objeto, a intenção é mostrar sua contribuição na construção de sentidos sobre a ditadura de 1964.

A construção do conceito de trauma cultural se dá a partir da compreensão de que as explicações anteriores não davam conta de mostrar que os fatos relacionados às atrocidades e às mudanças sociais numa sociedade são mediados emocional, cognitiva e moralmente pelos grupos condutores de discurso e têm status cultural. $\mathrm{O}$ processo de construção de sentido do trauma é mais cultural do que social, mais coletivo do que individual. As estruturas binárias propostas por Alexander (1993) - sagrado e profano, poluído e puro - indicam como os grupos competem para controlar os sentidos, classificação que iremos mostrar adiante.

Ao elaborar uma lista de expressões que tentam conduzir o discurso sobre a ditadura militar no cinema, iremos perceber a riqueza das colunas do que pode ser classificado como sagrado ou puro e mal ou poluido. Para entender as duas categorias, é preciso pensar na construção cultural do evento social ao longo do tempo, quando vai adquirindo um sentido de mal, ou seja, de algo que deve ser contido e evitado a todo custo, a convenção do que seria errado e deve ser expurgado. $\mathrm{Na}$ mesma lógica, o puro ou sagrado, aquilo que deve ser protegido e preservado, a convenção do que seria certo. Embora pareça uma classificação maniqueísta, Alexander (2005) afirma que a intenção é mostrar:

Como os grupos lutam para ganhar o con-
trole sobre as estruturas culturais, como eles
continuamente estão sujeitos às fissuras das
transformações históricas, ao padrão regu-
lativo dos campos institucionais, às políticas
econômicas da produção e distribuição, à
fragmentação da resposta da audiência, e a
eventos como guerras, revoluções, vitórias
ou derrotas eleitorais (Alexander, 2005, p.
23).

Existem duas formas do senso comum de pensar o trauma cultural: a perspectiva iluminista e a psicanalítica. $\mathrm{Na}$ primeira, há uma atitude racional, na qual se pensa em por fim ao trauma social vivido. Na segunda, a reação é o silêncio. A tendência é de que haja um hiato no tempo e somente após duas ou três décadas de ocorrido um episódio coletivo traumático ocorram reações. Enfim, o trauma nem sempre é percebido coletivamente durante o evento em si, mas após a passagem do tempo (Alexander, 2002b).

No Brasil, desde 1985, com a abertura democrática, surgem produções cinematográficas que vêm tentando elaborar os sentidos do período militar, além de outras que foram forçosamente abandonadas e retomadas, como Cabra Marcado para Morrer (Eduardo Coutinho) e outras que estavam censuradas. Passados mais de 20 anos do fim da ditadura, ainda está em processo a construção de narrativas acerca do fato e filmes continuam a ser 
rodados, como os que iremos observar a seguir - os filmes Zuzu Angel e Cabra-cega.

A ditadura militar como trauma cultural no cinema brasileiro

\section{A eclosão do golpe militar em 1964 coincidiu com um período de discussão sobre a culfura popular e 0 vigor do Cinema Novo. À época do Cinema Novo, o cineasta Joaquim Pedro de Andrade afirmava acreditar na arte como fator de transformação social (Moraes, 1989). 0 movimento promovia a construção de uma nova estética, a Estética da Fome, que trazia às telas a realidade das condições sociais do país: 30 milhões de analfabetos, uma crianẹa morta a cada 45 segundos de subnutrição e precariedade sanitária (Melo, 1990).}

A intenção era representar o momento históricopolítico-social brasileiro e levar o espectador a sair da sala de projeção senhor da realidade. Com o golpe, a cultura popular, tão exaltada, é alijada dos debates. Mas o Cinema Novo ainda sobreviveria como foco de resistência: "Os cineastas se aventuram em falar sobre tortura, repressão e o processo judiciário da época. O cinema passa a fazer um diagnóstico da derrota das esquerdas, mas já não existe uma ansiedade em conscientizar para a luta revolucionária" (Melo, 1990, p. 07).

O Ato Institucional n ${ }^{\circ} 5^{3}$ encarcera o cinema, sendo responsável pela censura de vários filmes. Com ironia e deboche, surge o Tropicalismo, proposta antropofágica de fazer arte. A Estética da Fome cede lugar à Estética do Lixo: vômitos, sangue, culto ao horror. Filmes como Desafio, de Paulo César Saraceni, Terra em Transe, de Glauber Rocha, e Pra frente Brasil, de Roberto Farias foram censurados. Estes filmes queriam textualizar fatos como a prisão de 50 mil pessoas no início da ditadura, a acusação de mais de sete mil, o indiciamento de outros 700 por crimes contra a segurança nacional, falar dos cassados e exilados. O parecer do censor Manoel Souza Leão afirma acerca do filme de Glauber Rocha:

\begin{abstract}
Captamos em seu contexto frases, cenas e situações com propaganda subliminar. Mensagens negativas e contrárias aos interesses da segurança nacional. Aspectos de miséria e de luta entre classes, além de um bacanal e de cenas carnavalescas e de amor são outros pontos inseridos no roteiro - com a finalidade única de enriquecê-lo e torná-lo suscetível ao grande público ávido de novidades na tela. Alguns diálogos chegam a ser agressivos, com insinuações contra a verdadeira e autêntica democracia. Outros fazem apologia à luta entre ricos e pobres. Várias mensagens têm origem nos conhecidos chavões de propaganda subversiva [...]. Consideramos o filme portador de mensagens contrárias aos interesses do País, motivo pelo qual deixamos de liberá-lo, aconselhando seja o mesmo examinado por elementos do Conselho se Segurança Nacional e pela douta chefia do SCDP [Serviço de Censura de Diversões Públicas] e Direção-Geral do DFSP [Departamento Federal de Segurança Pública] (Pinto, 2006, p. 83).
\end{abstract}

Por estas palavras, verificamos como o cinema ajudou a contar a história da ditadura militar. Até hoje a temática é revisitada: contemporaneamente, há filmes como Barra 68 - sem perder a ternura (2000), de Vladimir de Carvalho, Ação entre amigos (1998), de Beto Brant, e Alma Corsária (1994), de Carlos Reichenbach. Em 1997, o filme O que é isso companbeiro?, de Bruno Barreto, foi indicado ao Oscar de melhor filme estrangeiro da Academia de Cinema de Hollywood. Bons trabalhos - como Que bom te ver viva (1989), de Lúcia Morat, e Cabra marcado para morrer (19641984), de Eduardo Coutinho, elaboraram um discurso sobre o período. Ismail Xavier define o Cinema Novo: 
O CN foi a versão brasileira de uma política de autor que procurou destruir o mito da técnica e da burocracia da produção, em nome da vida, da atualidade e da criação. Aqui, atualidade era a realidade brasileira, vida era o engajamento ideológico, criação era buscar uma linguagem adequada às condições precárias e capaz de exprimir uma visão desalienadora, crítica, da experiência social. Tal busca se traduziu na 'estética da fome', onde a escassez de recursos técnicos se transformou em força expressiva e o cineasta encontrou a linguagem em sintonia com os seus temas (Xavier, 1985, p. 14).

Alguns grupos cujos discursos se tornaram relevantes no cenário midiático ajudaram a contar a história da ditadura e fazê-la presente no imaginário brasileiro, mesmo daqueles que não vivenciaram o período. Isso nos leva a classificar o processo ditatorial como drama social, partindo de um olhar sobre as narrativas do cinema nacional acerca do governo militar. $O$ passo seguinte, a sua confirmação como trauma coletivo, depende da reafirmação discursiva dos grupos que tentam legitimar o período como profano e poluído.

O conceito de trauma cultural se remete à perspectiva de Goffman $(1975$; 1988) acerca da dramaturgia como foco de pesquisa, indicando que o indivíduo desempenha um papel no qual o palco é o local das simulações. $\mathrm{Na}$ ditadura militar, o cinema vem produzindo nos últimos 40 anos filmes nos quais prevalece o sentido das representações coletivas acerca do governo militar: o filme é o local de performance social, onde atores cinematográficos incorporam atores sociais (vítimas e algozes). O roteiro é ditado pela história do Brasil.

\section{Passadas mais de três décadas do golpe, o vefor culfural vem moldando a economia e a política, uma vez que o evento leva a indústria do cinema a se}

apropriar de narrativas de vários episódios cuja temática é a ditadura militar para produzir filmes, reforçando novas leituras sobre o fafo. É este investimento sobre a construção discursiva do drama do golpe de 1964 que confirma a condiçc̃o determinante da cultura, a influência da arfe sobre a sociedade.

A pobreza com que se produziam filmes no Brasil na década de 70 e ainda nos anos 2000 comprova que a técnica mesmo não sendo rica, leva ao debate denso, e a discussão se concentra sobre o que falavam e não em como falavam. Assim como no Cinema Novo, isso se repetiu na produção cinematográfica sobre a ditadura militar. $\mathrm{O}$ período militar é tema de vários filmes e destacamos uma relação ilustrativa (quadro 1):
0 primeiro passo para a construscão do trauma culfural é a codificação do evento social como o mal, cafegoria que é construída a partir de produtos culfurais que 


\section{DOCUMENTÁRIOS}

Cabra marcado para morrer (1964/1984) documentário iniciado no começo da ditadura, interrompido em virtude da perseguição política e retomado 20 anos depois. A história narra a vida de um líder camponês assassinado e a clandestinidade de sua família durante o governo militar.

Jango (1984) - a história da deposição de João

Goulart e o início do governo militar.

O Evangelho segundo Teotônio (1984) - a trajetória do político no processo de abertura política brasileira.

Muda Brasil (1985) - documentário sobre o período de transição entre a ditadura e a volta da democracia.

Leila Diniz (1987) - a história da perseguição à atriz após declarações feitas no jornal O Pasquim.

História do Brasil vol VII (1993) - a República contemporânea, os anos do presidente Juscelino Kubitschek, a renúncia de Jânio Quadros, o golpe, as Diretas já e o retorno à democracia.

Tempo de resistência (2004) - fala sobre o golpe a partir do depoimento de mais de 30 pessoas envolvidas na resistência à ditadura. $\mathrm{O}$ filme aborda todo o processo, desde o golpe até a anistia, baseado no livro de Leopoldo Paulino.

\section{LONGAS}

Ação entre amigos (1998) - traz a história de quatro amigos que foram torturados durante o regime e o reencontro com o torturador.

Lamarca (1994) - Drama sobre a vida do capitão Carlos Lamarca, que deixa o Exército para ingressar na luta armada contra a ditadura militar do Brasil.

O que é isso companheiro? (1997) - a história de Fernando Gabeira, que participou do sequestro do embaixador americano Charles Elbrick, em 1969, por um grupo de militantes políticos.

Que bom de ter viva (1989) - a história do reencontro de militantes que anseiam em saber quem dentre elas sobreviveu da tortura. A própria diretora, Lúcia Murat, é uma das sobreviventes.

Cabra-cega (2005) - o filme mostra o período também chamado anos de chumbo e contextualiza o sofrimento de jovens envolvidos com o projeto revolucionário de luta contra a ditadura. Ficção.

Zuzu Angel (2006) - o período militar contado a partir da ótica de uma mãe, a estilista Zuzu, na tentativa de resgatar o corpo do filho militante político, torturado até a morte. Em sua busca, ela mesma é vítima da ditadura.

O ano em que meus pais saíram de férias (2006) conta a história de um menino cujos pais saíram e o fizeram acreditar que estavam de férias. Na verdade os pais de Mauro foram obrigados a fugir por serem de esquerda e serem perseguidos pela ditadura, Apenas o pai retorna. O filme, de Cao Hamburger, é uma obra de ficção.

Quadro 1 - Alguns filmes sobre a ditadura militar no Brasil. FONTE: Elaboração própria.

\section{viabilizam a constrụ̣ão do sentido.}

Esses produtos pertencem à indústria cultural e movimentam a economia de mercado: revistas, jornais, livros, filmes e a produção musical servem de espaço narrativo para o discurso que codifica a ditadura como o mal, o profano, o sujo, o poluído, que deve ser lembrado para não ser repetido.

No Brasil, as narrativas acerca do golpe foram sendo construídas por ambos os lados, militares e comunistas. Não há, entretanto, registro de filmes que tenham defendido a violência do regime militar. Há um sentimento de grupo que reúne torturados, exilados, parentes dos mortos, o que contribuiu para a se fortalecer a memória coletiva, ajudando na reconstrução simbólica dos fatos, feita através de artefatos culturais como o cinema. $\mathrm{Na}$ internet, as significações sobre o drama também aparecem: há mais de 970 mil 
citações para a expressão ditadura militar no Brasil. Ao associarmos a palavra cinema, são mais de 253 mil citações. No site http://novaescola. abril.com.br/especiais/regime_militar/_regime_militar. htm, da Fundação Victor Civita, afirma-se que "o cinema foi uma das muitas testemunhas do truculento período do regime militar".

É óbvio que durante a ditadura e nos primeiros anos após o seu fim, o controle da base material de produção simbólica estava nas mãos dos militares. Somente com a abertura democrática os filmes voltaram a ser produzidos e os grupos condutores de discurso conseguiram espaço no mercado cultural para produzir narrativas acerca dos eventos. E, se a ditadura não tivesse chegado ao fim e vivêssemos hoje em pleno governo militar, o mal não teria sido codificado e estaria ainda protegido em seus porões.

\section{Ao analisar a avidez do mercado cinemałográfico pela reconstrução do trauma culfural da difadura, percebe- se que o cinema preenche uma lacuna histórica na medida em que produz uma narrativa sobre o que foi 0 período militar no Brasil.}

Esta avidez permite que cineastas busquem investimentos para produzir discursos - os filmes acerca dos episódios, lotando salas de exibição com um público que, não tendo vivido diretamente a fase, a vivencia de forma mediada via cinema. Anne Kane afirma:

Eu compreendo narrativa, incluindo mitos, como histórias que incorporam códigos simbólicos. Assim, narrativas são configurações de sentido através da qual um indivíduo e/ou uma comunidade vem a compreender a si mesma. Narrativas também se constituem em um veículo de comunicação e interação entre os atores sociais (Kane, 2000, p.315).

É o que acontece nos filmes já citados Que bom te ver viva (1989), Cabra marcado para morrer (1964-1984) e Zuqu Angel (2006). Eles se encarregam de dilacerar a dor dos sobreviventes e mitificar as vítimas, desaparecidos políticos e torturados, agora personagens transformados em mitos. Nestes filmes, temos a exaltação do líder camponês João Pedro, da estilista Zuzu e seu filho, Stuart, todos assassinados durante o governo militar.

O trauma cultural, na condição de injúriaà coletividade, estabelece o lugar da vítima e do algoz, atribuindo responsabilidade e distribuindo as consequências ideais e materiais. E o trauma deixa lições: elas são objetivadas em monumentos, museus e peças culturais - como filmes - que ajudam a redirecionar o curso das ações políticas. Em que nível de mal a ditadura se encontra? O peso, a dimensão e a gradação do mal definem a responsabilidade, a punição, a ação remediadora e o comportamento futuro numa sociedade.

No Brasil, as iniciativas de Anistia, a luta pela abertura dos arquivos do Departamento de Ordem Política e Social (Dops), o pagamento de indenizações para sobreviventes e familiares das vítimas, o resgate da imagem de alguns mortos (Carlos Lamarca, Vladimir Herzog, Stuart Angel etc.), alguns deles elevados à condição de personagens-mártires de filmes, foram alternativas para o resgate da memória coletiva. Em 2010, ocorreu a criação da Comissão de Verdade, que visa a apurar os crimes de tortura e morte do período.

Entretanto, o que foi um trauma para as vítimas não foi para parte do público. Foi preciso que os grupos condutores do discurso construíssem uma narrativa progressiva da constituição de um novo mundo, uma nova ordem moral, a redenção dos que se sacrificaram, pensando uma sociedade de pós-golpe livre da "poluição" militar. Mas, o que é o mal e as ações traumatizantes? Quem foram os responsáveis e as vítimas? Quais os resultados das ações traumatizantes? O que pode ser feito para remediar ou prevenir a situação? São perguntas elaboradas nos filmes, construindo uma narrativa que atrai um público ávido por conhecer, de forma mediada, o drama social da ditadura militar brasileira. Em artigo 
de 27 de abril de 1997, Carlos Helí de Almeida e Luiz Fernando Vianna dizem que:

Nem todos os ex-militantes conseguiram trabalhar o tema da tortura sem traumas. A jornalista e cineasta Lúcia Murat, por exemplo, levou quase dez anos para dar sua visão no filme 'Que bom te ver viva'. Misto de documentário e ficção, o filme alinhava depoimentos de oito ex-presas políticas com falas de uma personagem fictícia e alter ego da diretora, interpretada por Irene Ravache. Agente do MR-8, Lúcia foi presa em 1971 e torturada nos dois primeiros meses dos três anos e meio que passou na prisão. 'Que bom te ver viva' é o resultado de sete anos de psicanálise (Site www.cinemabrasil.org. br).

A metodologia de investigação numa perspectiva dicotômica de classificação - o sagrado e o profano organiza a vida cultural. Os processos comunicativos se dirigem para a metafísica e a moralidade, o sentimento público e a significação pessoal e permite que os processos culturais se tornem centrais na vida política contemporânea.

\section{Num sentido amplo, a mídia funciona como recurso para investigação das representações coletivas que são feitas sobre os fatos sociais,}

mídia essa que engloba todas as formas de expressão cultural: cinema, teatro, literatura, imprensa, música. Juntos, estes artefatos ajudam a construir narrativas da ditadura como drama social que pode assumir a condição de trauma cultural.

\section{Cabra-cega e Zuzu Angel}

A nossa intenção não é construir uma análise sobre a circulação, o consumo e a resposta social aos filmes, mas observar a presença das duas dimensões de percepção do discurso definidas por Alexander (sagrado e profano),

indicando a existência de expressões que encaminhem a ditadura para o sentido de trauma cultural. Nos dois filmes escolhidos - Cabra-cega, de Toni Venturi, e Zũu Angel, de Sérgio Rezende - estas expressões são recorrentes e formalizam uma rede de significação que comprova a relação binária de bem e mal, sagrado e poluído, colocando a realidade num texto denso, mas compreensível como trauma mesmo para os que não viveram os episódios da época. Elas carregam o mesmo sentido, sendo repetidas nas duas obras, conforme

\begin{tabular}{|l|}
\hline SAGRADO \\
\hline $\begin{array}{l}\text { Militância, militante, revolução social, luta política, esquerda, ação, causa, compromisso, grupo de ação, povo, } \\
\text { companheiro, organização, resistência, a luta continua, movimento estudantil, revolução socialista, guerra } \\
\text { revolucionária, guerra pelo socialismo, protesto, socialismo, comunismo. }\end{array}$ \\
\hline \\
\hline PROFANO \\
\hline $\begin{array}{l}\text { Ditadura militar, tortura, choques elétricos, morte, prisão, repressão, desaparecimento de militantes, fuga, } \\
\text { perseguição, violência, medo, porcos imperialistas, gringos, censura, horror, impunidade, aceitação, adesismo, } \\
\text { revolução democrática, terrorismo, líderes do terror, inimigos da democracia }\end{array}$ \\
\hline
\end{tabular}

Quadro 2 - O sagrado e o profano nos filmes Zuzu Angel e Cabra-cega. Fonte: Elaboração própria.

quadro 2:abra-cega. Fonte: Elaboração própria.

As representações precisam ser naturalizadas para serem associadas a algo existente previamente de modo a que os indivíduos se apropriem do sentido. Há uma competição pelo controle simbólico do sentido que prevalece pelos grupos condutores do discurso: aqueles que foram a favor do regime militar e os que foram contra. E, mesmo entre os contrários ao golpe, há uma diversidade de sentidos que podem circular. O que distingue a hermenêutica das ciências humanas do método das ciências naturais é o desafio de penetrar além da forma até o sentido profundo das ações e instituições, sentidos governados pela estrutura. O esforço interpretativo das ciências sociais deve começar 
pela reconstrução de uma estrutura cultural.

O bem e o mal vão sendo definidos, quando fica clara a codificação da ditadura: tortura, limitação das liberdades e censura constituem o poluído, o profano, e a codificação da democracia: o universalismo como algo bom, sagrado.

\section{Os filmes ocupam o espaço da indústria cinematográfica e ganham o mercado cultural com a narrativa de episódios de violência e forfura, da miséria dos porões, das perseguições e do exílio imposto às lideranças políticas de oposição.}

Há um processo de construção de narrativa por um viés simbólico: os militares eram a incorporação do mal; os membros da esquerda brasileira, as vítimas.

A representação cinematográfica tende a localizar e particularizar o trauma dos sobreviventes e mortos pela violência política, ao mesmo tempo em que universaliza o episódio ao elaborar termos como ditadura, golpe, redentora, anos de chumbo, chuva de chumbo como forma de definir o mal e se contrapor ao discurso oficial da revolução. O peso acerca do sentido da violência no período militar é generalizado e reificado. Começa a ser entendido como único, como evento sem precedentes, como mal numa escala que nunca ocorreu antes e que precisa ser registrado na história. A narrativa trágica do cinema oferece o que Nietzsche chamou de drama do eterno retorno, a volta ao eterno drama traumático como forma de impedir sua repetição - transformando o arquétipo do sagrado-mal de nosso tempo, colocando-o numa contínua existência a partir de sua revivescência. Para Xavier, "agora, viver no Brasil é encarar a tortura, a agonia, o tempo como um sangrar, lento e ininterrupto. O passado é ruína; a redenção futura, um ponto de fuga ilusório" (Xavier, 1985, p. 22).

Algumas cenas e diálogos nos dois filmes servem para a percepção simbólica dos fatos. Em ambos, há um misto de cenas de ficção e da realidade que, misturadas, indicam que a realidade está sendo contada ali, um complexo de significação que eleva os filmes à condição de recorte da vida real. No filme Cabra-cega, a narrativa é embalada pela música Roda Viva, de Chico Buarque. As cenas reais e construídas trazem militares com tanques de guerra e militantes a pé, num confronto que simboliza a luta do mais fraco, de mãos dadas e bocas lacradas com adesivos para indicar o silenciamento provocado pela repressão. Em Zuzu Angel, a música, também de Chico Buarque, é Angélica, que fala da mãe que luta para enterrar o filho morto e jogado ao mar. Chico a compôs para a estilista, sua amiga pessoal.

O texto da vida brasileira nas décadas de 60 e 70 é reafirmado nas manchetes dos jornais apresentados, no noticiário de TV: nos dois filmes, o assassinato do capitão do Exército Carlos Lamarca, guerrilheiro que se transformou em líder da esquerda e foi morto, é mostrado para a audiência. Em Cabra-cega, o enredo conta a história fictícia - mas provável - do militante Tiago, codinome Roberto, que está traumatizado por estar confinado em um esconderijo sem poder ir à luta clandestina contra a ditadura. Em Zuqu Angel, a estilista de moda passa de alienada a militante política, a partir da tortura e morte de seu filho.

$\mathrm{Na}$ cor do cenário, uma mensagem: segundo o diretor de arte do filme, Marcos Flaksman, o verde é a cor do ambiente até que chegue a notícia da morte de Stuart. Com a descoberta do crime, Zuzu passa a usar vermelho e o cenário tem paredes no mesmo tom - a cor do comunismo e também do sangue. O cartaz que mostra fotos de procurados por terrorismo é igual nos dois filmes, com a frase: “Terroristas procurados. Ajude a proteger a sua vida e a de seus familiares". Abaixo, trechos de diálogos dos filmes (quadro 3):

Estas falas nos aproximam da história do país.
A dramatizascão do episódio como uma fragédia e sua representação discursiva no cinema permifem a generalização e a universalização dos episódios, transformando-os em ícones do sofrimento e do trauma da 
“As ditaduras só trocam de lugar, mesmas disputas, mesmas perdas" - d. Nenê, Cabra-cega;

"A história não vai perdoar quem fica em cima do muro" - Tiago/Roberto, Cabra-cega;

"Aos muitos brasileiros, cabras-cegas, que tentaram atravessar a escuridão para tomar os céus de assalto" - frase final do filme Cabra-cega;

"Não há liberdade, os artistas estão sendo perseguidos. O povo vai dar um basta em tudo isso" Stuart/Paulo, Zuzu Angel;

"Nós estamos em guerra contra a subversão. Por isso, aplico a Convenção de Genebra para os nossos prisioneiros ao pé da letra" - oficial do Exército, em diálogo com Zuzu Angel;

"Tudo isso que se diz sobre as prisões é propaganda comunista [...]. As torturas que tanto falam não é nada disso. Os tais choques são levinhos, uma maquininha à toa, não mata ninguém" - capelão da Aeronáutica, em diálogo com Zuzu Angel;

"O senhor não representa a Igreja brasileira, que nunca apoiou a tortura" - resposta ao capelão dada por Zuzu Angel;

"Nossos sonhos compensam qualquer sacrifício" - Stuart Angel, em Zuzu Angel;

"O poder de mudar o curso da história é o poder de Deus. Eu me curvo diante desse poder" Stuart Angel, em Zuzu Angel.

Quadro 3 - Os diálogos nos filmes Zuzu Angel e Cabra Cega e a construção de sentidos.

\section{sociedade brasileira.}

É importante ressaltar que não é uma mão invisível que constrói o trauma narrativamente, ele emerge aos pedaços: reportagens, livros, episódios de TV, performances teatrais, fotos que circulam e se tornam motivo de debate são roteirizados para o cinema e pautam as agendas pessoais de preocupações. A tortura, no processo de construção narrativa, é mostrada como violência sistemática e organizada contra membros de um grupo estigmatizado, os comunistas. $\mathrm{O}$ crime não é apenas legal, mas moral. Em 1965, a recomendação abaixo, publicada na Revista aParte (1968), foi feita aos cineastas brasileiros:

Um filme nacional não deve [...] ser portador de mensagem política incompatível com o regime vigente no país ou que de qualquer forma fira a dignidade brasileira ou venha a apresentar riscos à segurança nacional (discurso do chefe do Departamento Federal de Segurança Pública, general Riograndino Kruel, em 09 de abril de 1965. Revista aParte. São Paulo: TUSP, mai-jun 1968).

Anteriormente, segundo depoimento de Roberto Farias a Leonor Souza Pinto, o crítico de cinema francês Georges Sadoul aconselhou aos cineastas, em 1964, durante o Festival de Cannes: "façam seus filmes, como for possível. Não parem. Porque um dia isso vai passar, e nesse dia, seus filmes estarão lá para contar essa história" (Sadoul apud Pinto, 2006, p. 92). Como condutores de discurso da história do Brasil, os cineastas desobedeceram ao general e seguiram o conselho do crítico francês. Em depoimento no making of do filme Zuzu Angel, Sérgio Rezende afirmou sobre a personagem principal:

Uma personalidade [...] que no começo dos anos 70 se vê no olho do furacão, o período negro da vida brasileira, da ditadura. $\mathrm{O}$ Stuart, seu filho mais velho, que já vinha do movimento estudantil, de repente com o AI-5 e a censura, cai na luta armada. Depois é preso, barbaramente torturado e tem um fim trágico [...]. Eu acho que esse roteiro, embora claramente situado nesses anos negros da vida brasileira, mostra que a história da Zuzu é universal e atemporal (Sérgio Rezende, entrevista no making of do filme).

O diretor de Cabra-cega, Toni Venturi, também fala do seu filme:

Passado o período mais agudo da repressão, agora é que estamos preparados para refletir sobre ele [...]. Queríamos mostrar para as pessoas que vale a pena sonhar, que vale a pena lutar [...]. Chegou o momento em que a sociedade brasileira parece que está preparada para fazer uma revisão daqueles episó- 
dios que o Brasil passou durante a ditadura militar (Toni Venturi, entrevista no making of do filme).

\section{Considerações finais}

\section{0 reforno regular da ditadura às telas de cinema é como o coração pulsante de alguém que nunca morre.}

O ritual que pode purificar as vítimas é a retrospectiva, o que permite uma catarse e um re-julgamento de episódios traumáticos. O drama social é perpetuado a partir de monumentos e cerimônias de homenagem. O processo de memorização é feito através de filmes, livros e discursos dos sobreviventes via mídia. Narrativa que emerge entre a aliança da testemunha e do entrevistador: história de vida que comunica a história das pessoas que sobreviveram, um particularismo que estrutura o universalismo e o transforma em história.

A intenção do discurso midiático é de escancarar arquivos, abrir os olhos dos telespectadores que não viveram o drama da ditadura, trazendo às telas os atores sociais, agentes históricos como porta-vozes de um discurso que, passados 40 anos, sobrevive na memória coletiva.

\section{A história está sempre por ser confada e eventos traumáticos como a difadura brasileira, assim como 0 Holocausto e a guerra do Viefnã, são femas recorrentes que precisam ser narrados e reprisados para se fixarem na memória coletiva de cada sociedade.}

É evidente que a cultura funciona aqui como variável determinante de outros elementos da estrutura - a política e a economia - e que deve ser um ponto de resistência e de elaboração discursiva dos traumas culturais. Essa percepção da cultura como elemento estruturante fortalece o contingenciamento dos grupos condutores do discurso, líderes que podem, através de peças culturais, apresentar a realidade como um texto a ser significado.

No caso da ditadura, os cineastas foram os carrier groups - os porta-vozes e muitas vezes as próprias vítimas dos roteiros que construíram para apresentar a vida real como drama em cena. Nesta análise, a intenção era de mostrar o estabelecimento da ditadura como drama social, através da construção narrativa do cinema nacional e o seu papel no processo de transição do drama para o trauma coletivo, ao se somar aos discursos de outros meios capazes de sustentar este sentido. A significação da ditadura militar, porém, levará alguns anos para se concretizar (ou não) como trauma cultural para poder ser efetivamente estudada.

\section{NOTAS}

${ }^{1} \mathrm{O}$ contrato de leitura é um vínculo implícito entre o leitor/espectador e a mídia, renovado regularmente a partir das expectativas do indivíduo em relação ao conteúdo do meio. Ele se renova pela ida ao cinema para assistir filmes com abordagem específica, pela compra de determinado jornal, acesso ao jornal on-line ou audiência ao rádio ou à TV. O contrato contém cláusulas tácitas, como a hierarquização dos assuntos abordados pelos meios de comunicação.

${ }^{2}$ A Comissão de Verdade foi instituída durante o governo de Luís Inácio Lula da Silva.

${ }^{3}$ Decretado em 13 de dezembro de 1968.

\section{REFERÊNCIAS}

ADORNO, Theodor. Indústria Cultural e Sociedade. São Paulo: Paz e Terra, 2002.

ALEXANDER, Jeffrey. C., SMITH, Philip. \& SHERWOOD, Steven. J. Risking Enchantment: Theory and Method in Cultural Studies. In: Culture: the Newsletter of the Sociology of Culture, v.08, n.01, p. 10-14, Set. 1993. Disponível em: <http://research.yale.edu/ccs/alexander/ articles/>. Acesso em: 22 set 2006.

ALEXANDER, Jeffrey. C. \& SMITH, Philip. The Strong Program in Cultural Theory: Elements of a Structural Hermeneutics. In: TURNER, J. H. (org). Handbook 
of Sociological Theory. New York, Kluwer Academics/ Plenum Publishers, mar. 2002a. Disponível em: <http:// research.yale.edu/ccs/alexander/articles/> . Acesso em: 22 set. 2006.

ALEXANDER, Jeffrey. C. Towards a Theory of Cultural Trauma.2002b. Disponível em: < http://research.yale.edu/ ccs/alexander/articles/>. Acesso em: 23 set. 2006.

ALEXANDER, Jeffrey. C. On the Social Construction of Moral Universals: the 'Holocaust' From War Crime to Trauma Drama. In: European Journal of Social Theory, v.5, n.1, p. 5-85. Periódicos CAPES, 2002c.

ALEXANDER, Jeffrey. C. Why Cultural Sociology Is Not 'Idealist': a Reply to McLennan. In: Theory, Culture \& Society, v.22, n.6, p. 19-29. Periódicos CAPES, 2005.

ALMEIDA, C. H. de \& VIANNA, L. F. Memória de Chumbo. Disponível em: <www.cinemabrasil.org.br>. Acesso em: 13 jan. 2007.

BARROS FILHO, Clóvis de. \& MARTINO, Luis Mauro Sá. O habitus na comunicação. São Paulo: Paulus, 2003.

FOUCAULT, Michel. A ordem do discurso. São Paulo: Loyola, 1996.

FUNDAÇÃO VICTOR CIVITA. O dia que durou 21 anos. Disponível em: <http://novaescola.abril.com.br/ especiais/regime_militar/regime_militar.htm $>$. Acesso em: 22 set. 2006.

GOFFMAN, Erving. A representação do eu na vida cotidiana. Petrópolis: Vozes, 1975.

GOFFMAN, Erving. Estigma: notas sobre a manipulaşão da identidade deteriorada. Rio de Janeiro: LTC, 1988.

\section{GOVERNO PROPÕE CRIAÇÃO DE COMISSÃO} DA VERDADE SOBRE REGIME MILITAR. Disponível em: $\quad<$ http://ultimosegundo.ig.com.br/ bbc/2009/12/21 /verno+propoe+criacao+de+comissao+da + verdade + sobre + regime + militar $+9251571 . h t m l>$. Acesso em: 21 jan. 2010.

HABERMAS, Jurgen. Mudança estrutural da esfera pública: investigacõos quanto a uma categoria da sociedade burguesa. Rio de Janeiro: Tempo Brasileiro, 1984.
JACOBS, M. D. \& SPILLMAN, L. Cultural Sociology at the Crossroads of the Discipline. In: Poetics, v.33, n.1, p. 1-14. Periódicos CAPES, 2005.

KANE, Anne. Cultural analysis in Historical Sociology: the analytical and concrete autonomy of culture. In: Sociological Theory, v.9, n.1, p. 53-69. Periódicos CAPES, 1991.

KANE, Anne. Reconstructing culture in historical explanation: narratives as cultural structure and practice. In: History and Theory, v.39, n.3, p. 311-330. Periódicos CAPES, 2000.

MILAN, Elizabeth. Revista aParte. São Paulo: TUSP, mai-jun 1968.

MELO, Patricia Badeira de. Uma paixão em $8 \mathrm{~mm}$. Recife: UFPE, mimeo, 1990.

MORAES, Dênis. A Esquerda e o Golpe de 64. Rio de Janeiro: Espaço e Tempo, 1989.

PINTO, Leonor Souza. O cinema brasileiro face à censura imposta pelo regime militar no Brasil 1964/1988. In: CHAGAS, C. M. de F., ROMÃO, J. E. E. \& LEAL, S. (orgs). Classificação Indicativa no Brasil: desafios e perspectivas. Brasília: Ministério da Justiça, 2006.

SOBRE A ANISTIA E A COMISSÃO DA VERDADE. Disponível em: <http://www.cartamaior. com.br/>. Acesso em: 21 jan. 2010.

SZTOMPKA, Piotr. Cultural Trauma: the Other Face of Social Change. In: European Journal of Social Theory, v.3, n.4, p. 449-466. Periódicos CAPES, 2000.

XAVIER, Ismail, BERNARDET, Jean-Claude \& PEREIRA, Miguel. Os desafios do cinema: a política do Estado e a política dos autores. Rio de Janeiro: Jorge Zahar, 1985.

Filmes:

VENTURI, Toni. Cabra-cega. Brasil: Olhar Imaginário, Europa Filmes, 2004.

REZENDE, Sérgio. Zuzu Angel. Brasil: Globo Filmes, Warner Bros, 2006.

* Todas as citações diretas feitas a partir do original em inglês foram traduzidas pela autora. 